\title{
Anatole Katok Center for Dynamical Systems and Geometry
}

\section{Svetlana Katok and Yakov Pesin}

\section{Creation of the Center}

The Penn State research group in dynamical systems was formed in 1990 when Anatole and Svetlana Katok, Yakov Pesin, and Howard Weiss moved to Penn State to join Eugene Wayne who already was there. By that time Anatole had already established himself as a leader in dynamical systems who had co-organized several major events (such as a year program in dynamics at MSRI in 1983-84) and had trained a number of graduate students and postdocs at University of Maryland and Caltech. He came to Penn State with the plan to build a strong group in dynamics and to attract talented young mathematicians to the subject. Full of energy and ideas, he immediately started a weekly seminar in dynamical systems and was thinking of organizing some major scientific meetings.

At that time the mathematics department of the University of Maryland had an active group of researchers working in dynamical systems with whom Anatole had had close scientific relations. Anatole came up with the idea of organizing biannual workshops in "Dynamical Systems and Related Topics" as a joint enterprise of the two mathematics departments with fall workshops held at Penn State and spring workshops held at Maryland. The first such meeting happened in the fall of 1991.

Other major events were the AMS Summer Workshop on Dynamical Systems organized by Anatole jointly with

Svetlana Katok is a professor of mathematics at Pennsylvania State University. Her email address is sxk37@psu. edu.

Yakov Pesin is a Distinguished Professor of Mathematics at Pennsylvania State University and director of the Anatole Katok Center for Dynamical Systems and Geometry. His email address is pesin@math. psu.edu.

For permission to reprint this article, please contact: reprint - permission@ams.org.

DOI: https://dx.doi.org/10.1090/noti 1870
Yakov Pesin and Howard Weiss in Seattle in 1999 and the International Conference "Ergodic Theory, Geometric Rigidity, and Number Theory," which was co-organized by Anatole at Newton Institute (Cambridge, UK) in July, 2000.

Within a few years after its creation, the dynamics group at Penn State had grown and so had its activities. This included a visitor program, intensive collaborations, a weekly seminar, etc. The group also had a large number of graduate students interested in dynamics. In early 1990, due to the fall of the Soviet Union, many undergraduates from Eastern European countries had the opportunity to pursue a PhD in the West. Quite a few came to Penn State, which was already known for its extensive program in dynamics.

In 1997, after being named Raymond S. Shibley Professor of Mathematics, Anatole Katok initiated the creation of the Center for Dynamical Systems (the Center) at Penn State and became its director. A few years later the Center was expanded to become the Center for Dynamical Systems and Geometry, which has now become one of the major centers in dynamics in the US.

At the time the Center was created Anatole Katok wrote a memo in which he stated the Center's goals as follows:

- To stimulate research in the theory of dynamical systems and related areas at Penn State.

- To serve as a forum for the exchange of ideas and discussion of achievements within the worldwide dynamical systems community.

- To foster interaction, exchange of ideas, and joint projects between mathematicians and researchers in other areas interested in non-linear dynamics.

- To disseminate the knowledge of the achievements in dynamical systems theory within the scientific community.

- To contribute to the training of the next generation of researchers in dynamical systems and related areas. 


\section{Financial Support and Endowments}

Initially, the financial support for the Center's activities came primarily from Katok's departmental fund and his fund as Raymond S. Shibley Professor, while the financial support for the fall workshop came primarily from the NSF. After Anatole Katok's untimely death, three donors have stepped forward to make generous gifts in Katok's memory totaling $\$ 2.7$ million.

- A lead gift of $\$ 2$ million came from Michael Brin, a colleague and former student of Katok, who endowed the Anatole Katok Chair in Mathematics in the Eberly College of Science with the goal of supporting outstanding faculty members who are leaders in the study of dynamical systems, as Katok was throughout his career.

- Additional contributions totaling \$700,000 came from Brin and two of Katok's other former students, Sergey Ferleger and Alexey Kononenko, to provide permanent program support for the Center for Dynamical Systems and Geometry, which now bears Anatole Katok's name.

- Additional matching funds came from the Eberly College of Science.

Penn State University and, in particular, its Eberly College of Science were instrumental in helping to build the Center with the goal of preserving Anatole Katok's legacy and his outstanding contributions to mathematics.

"The endowment from Michael, Serge, and Alexey will honor Anatole's memory and extend his legacy in perpetuity," said Douglas Cavener, dean of the Eberly College of Science.

"These meaningful gifts to honor the late Dr. Anatole Katok will propel cutting-edge mathematics research for generations to come," said O. Richard Bundy III, vice president for development and alumni relations. "This is a fitting way, indeed, to honor a professor and mentor who was profoundly respected by so many not only at Penn State, but throughout the mathematics world."

"Anatole was an extraordinary academic and contributed great value to his profession," said Brin. "Through these gifts, Alexey, Serge, and I hope to honor his outstanding legacy by supporting faculty members who will continue the research and teaching to which he devoted his life."

\section{The Center Structure and Programs}

The Anatole Katok Center for Dynamical Systems and Geometry at Penn State has a strong and active group of faculty working in a broad spectrum of disciplines related to dynamical systems and geometry. At present, the Center consists of 14 faculty members, 7 associate members, 14 graduate students, and a postdoc. Yakov Pesin is its current director. The Center has a broad research program that includes:

- A visitor program (about 10 short- and long-term visitors a year)

- A weekly Dynamical Systems Seminar
- Center for Dynamics and Geometry Colloquium at which talks are given about once a month by distinguished invited speakers

- Working Seminar: "Dynamics and its Working Tools," which operates "in old Russian style" where each lecture lasts about two hours and includes all relevant details

- Dynamics Student Seminar organized by students interested in dynamical systems

- Basic courses in dynamical systems and related topics at graduate and undergraduate levels, special topic courses and special lecture series (on an annual basis)

- An annual workshop in "Dynamical Systems and Related Topics." Starting as regional meetings, these workshops have now grown into major national conferences on dynamical systems with many participants coming from all over the world.

In the last several years during these workshops two major prizes in dynamical systems have been awarded: Michael Brin Prize in Dynamical Systems (for researchers no more than 14 years from their PhD) and Michael Brin Dynamical Systems Prize for Young Mathematicians (no more than 4 years from their PhD). The monetary fund for these two awards came from the endowments established by Michael Brin, and these are the two major and highly prestigious awards for young mathematicians working in dynamical systems.

For more information on Anatole Katok Center for Dynamical Systems and Geometry see https://math .psu.edu/dynsys.

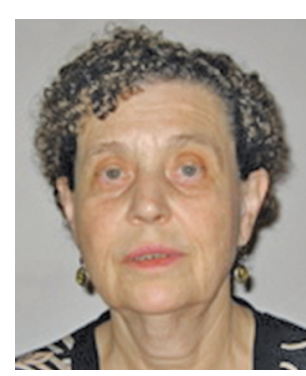

Svetlana Katok

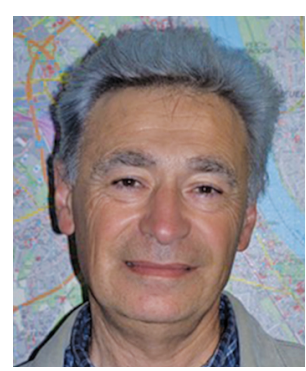

Yakov Pesin
AUTHOR NOTE: We are happy to report that Federico Rodriguez Hertz has accepted the position of the Anatole Katok Chair in Mathematics. His appointment started April 1, 2019.

\section{Credits}

Photos of Svetlana Katok and Yakov Pesin are courtesy of the authors. 